\title{
SISTEMAS ATMOSFÉRICOS ATUANTES E DIVERSIDADE PLUVIOMÉTRICA EM SERGIPE
}

\author{
ACTING ATMOSPHERIC SYSTEMS AND RAINFALL DIVERSITY IN SERGIPE
}

SISTEMAS ATMOSFÉRICOS ACTUANTES Y LA DIVERSIDAD

DE ILUVIA EN SERGIPE

\author{
Marco Túlio Mendonça Diniz - Universidade Federal do Rio Grande do Norte - \\ Caicó - Rio Grande do Norte - Brasil \\ tuliogeografia@gmail.com
}

Sebastião Carlos de Medeiros - Universidade Federal do Rio Grande do Norte -

Caicó - Rio Grande do Norte - Brasil

cmedeiro.pm@hotmail.com

Cleidinilson de Jesus Cunha - Instituto Federal de Educação, Ciência e Tecnologia da Bahia -
Paulo Afonso - Bahia - Brasil
cleidinilson13@gmail.com

\section{Resumo}

Este trabalho visa a demonstrar a importância dos sistemas atmosféricos na constituição dos tipos climáticos do estado de Sergipe, bem como a sua distribuição. Foram utilizados dados pluviométricos mensais da série histórica da Superintendência do Desenvolvimento do Nordeste (Sudene) que tiveram suas médias calculadas pelo Departamento de Ciências Atmosféricas da Universidade Federal de Campina Grande. A duração da estação seca foi calculada com base no índice xerotérmico, de Gaussen e Bagnouls (1953). Mapas temáticos foram elaborados utilizando os dados da Sudene, bem como softwares de Sistema de Informação Geográfica. 0 regime pluviométrico e a duração da estação chuvosa, no estado de Sergipe, variam de acordo com a época do ano e a localização geográfica. 0 índice de precipitação se distribui de forma decrescente do litoral para 0 interior do estado, evidenciando 0 efeito da continentalidade na distribuição das chuvas, o que ficou evidenciado nos mapas temáticos.

Palavras-chave: climatologia regional, climatologia do Nordeste, climas de Sergipe.

\section{Abstract}

The present study aims at demonstrating the importance of atmospheric systems in the climate type constitution in Sergipe state, as well as how the distribution of these systems occurs. We used monthly rainfall data from Superintendência do Desenvolvimento do Nordeste (Northeast Development Superintendence) - SUDENE historical series. These data average was calculated by The Atmospheric Science Department of Campina Grande Federal University. The duration of the dry season was calculated based on Gaussen and Bagnouls's xerothermic index. Thematic maps were produced using data from SUDENE in addition to Geographic Information System software. The rainfall regime and duration of the rainy season in Sergipe state vary according to season and geographical location. The precipitation rate is distributed in descending order from the state coast to the interior, showing the effect of continentality on the distribution of rainfall, evidenced in thematic maps.

Key words: regional climatology, Northeast climatology, climate of Sergipe.

\section{Resumen}

Este estudio tuvo como objetivo demostrar la importancia de los sistemas meteorológicos en la constitución de los tipos climáticos del estado de Sergipe, así como su distribución. Hemos utilizado los datos de precipitación 
mensual de la serie de Superintendência do Desenvolvimento do Nordeste (Superintendencia de Desarrollo de Nordeste) - SUDENE que tuvo sus promedios calculados por el Departamento de Ciencias Atmosféricas de la Universidad Federal de Campina Grande. La duración de la estación seca se calculó basándose en el índice xerotérmico de Gaussen y Bagnouls. Los mapas temáticos fueron producidos utilizando los datos de SUDENE y software de sistema de información geográfica. La precipitación y la duración de la temporada de lluvias en el estado de Sergipe varían según la época del año y la ubicación geográfica. La tasa de precipitación se distribuye en orden descendente desde la costa hacia el interior del estado, que muestra el efecto de continentalidad en la distribución de las lluvias que se evidenció en los mapas temáticos.

Palabras clave: climatología regional, climatología do Noreste, climas de Sergipe.

Introdução

O clima do Nordeste do Brasil (NEB) apresenta acentuada variabilidade interanual, particularmente na precipitação, com alguns anos extremamente secos e outros extremamente chuvosos. Essa é também uma das regiões da América do Sul onde os sinais da variabilidade intrassazonal são mais evidentes.

Os mecanismos dinâmicos que produzem chuvas no NEB podem ser classificados em mecanismos de grande escala, mesoescala e microescala, sendo os primeiros responsáveis pela maior parte da precipitação observada (Molion e Bernardo, 2002).

Dentre os mecanismos de grande escala, destacam-se a atuação da Zona de Convergência Intertropical (ZCIT) e dos sistemas frontais ou frentes frias. Perturbações Ondulatórias no Campo dos Ventos Alísios (POA), brisas marinhas e terrestres fazem parte da mesoescala, ao passo que as circulações orográficas são exemplos de mecanismos de microescala.

O estado do Sergipe tem seu clima classificado como tropical litorâneo do Nordeste Oriental (Mendonça e Danni-Oliveira, 2007), que varia bastante na quantidade de meses secos durante o ano, mesmo em um estado de pequena expressão geográfica, já que é o menor da federação, com área de 22.050,4 km, localizado no leste da Região Nordeste, com equivalência de $0,26 \%$ do Território Nacional e 1,43\% da Região Nordeste.

Quanto à posição, Sergipe situa-se entre as latitudes sul de $9^{\circ} 31^{\prime} \mathrm{e}$ $11^{\circ} 34^{\prime \prime}$ e as longitudes oeste de $36^{\circ} 25^{\prime}$ e $38^{\circ} 14^{\prime}$, cujos pontos extremos são estes: ao norte, a barra do Rio Xingó, em Canindé de São Francisco; ao sul, a curva do Rio Real, no povoado Barbeiro em Cristinápolis; ao leste, a barra do Rio São Francisco, na ilha de Arambipe, em Brejo Grande; ao oeste, a curva do Rio Real, no povoado Terra Vermelha, em Poço Verde. 
O estado de Sergipe possui 75 municípios: alguns apresentam grande extensão, como Poço Redondo (1.224,4 km²), Lagarto $\left(939,8 \mathrm{~km}^{2}\right)$, Porto da Folha (892,5 km²), e outros são pequenos como General Maynard $\left(18 \mathrm{~km}^{2}\right)$, Pedrinhas $\left(33,2 \mathrm{~km}^{2}\right)$, Riachuelo $\left(31 \mathrm{~km}^{2}\right)$ e Amparo do São Francisco $\left(39,3 \mathrm{~km}^{2}\right)$, que foram agrupados em oito territórios (Figura 1).

Figura 1: Divisão do estado em territórios de planejamento.

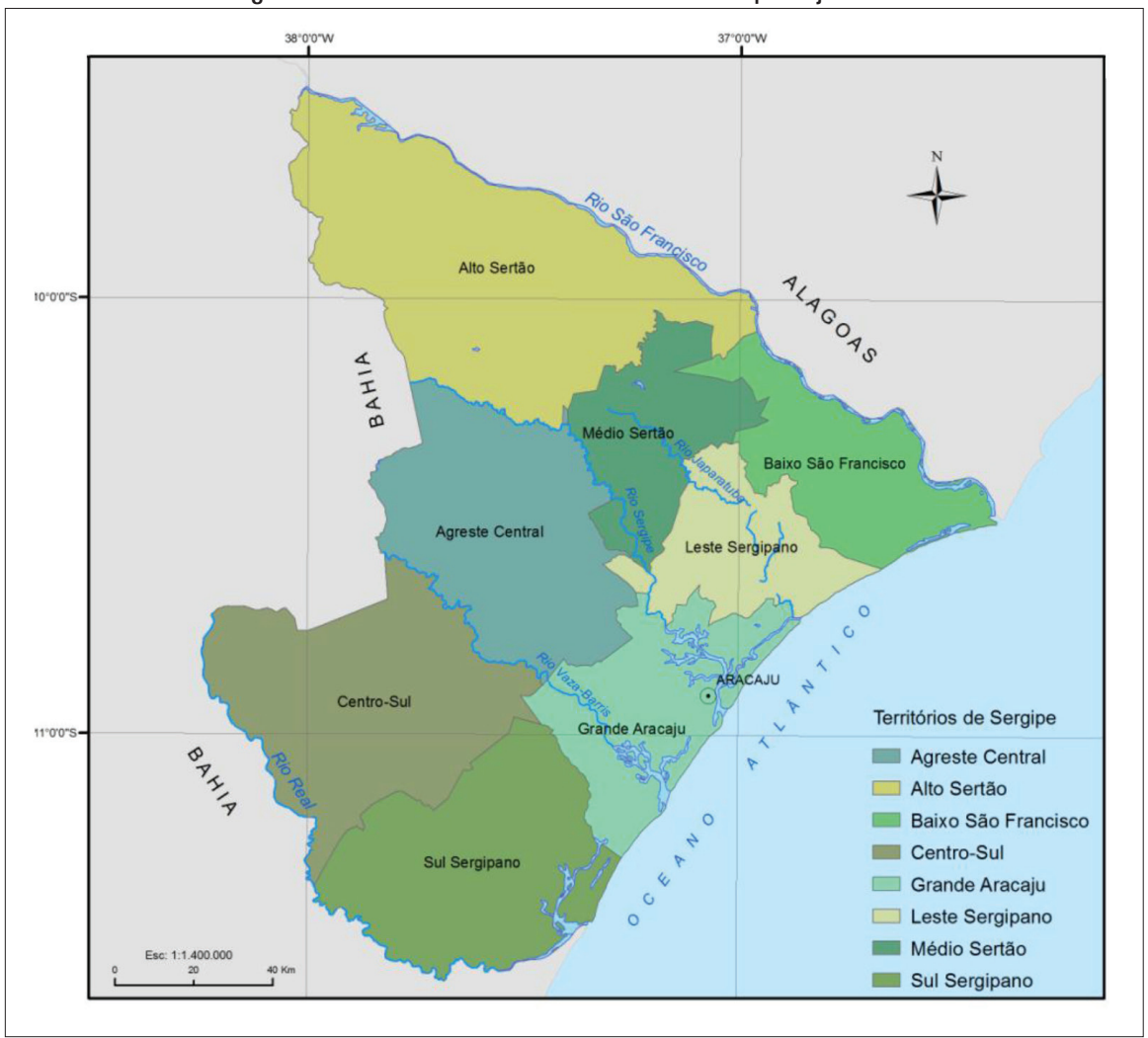

Fonte: Sergipe (2011).

Materiais e métodos

Para a compreensão do clima de Sergipe, foi feito um estudo detalhado a respeito desse assunto para esclarecer melhor os sistemas promotores de chuva no estado, assim como os fatores geográficos que 
influenciam nos totais pluviométricos. Para estabelecer a variação da precipitação no Estado, foram obtidos dados referentes à temperatura e precipitação de 23 postos pluviométricos distribuídos entre o litoral e o interior de Sergipe (Figura 2).

Figura 2: Localização dos postos pluviométricos.

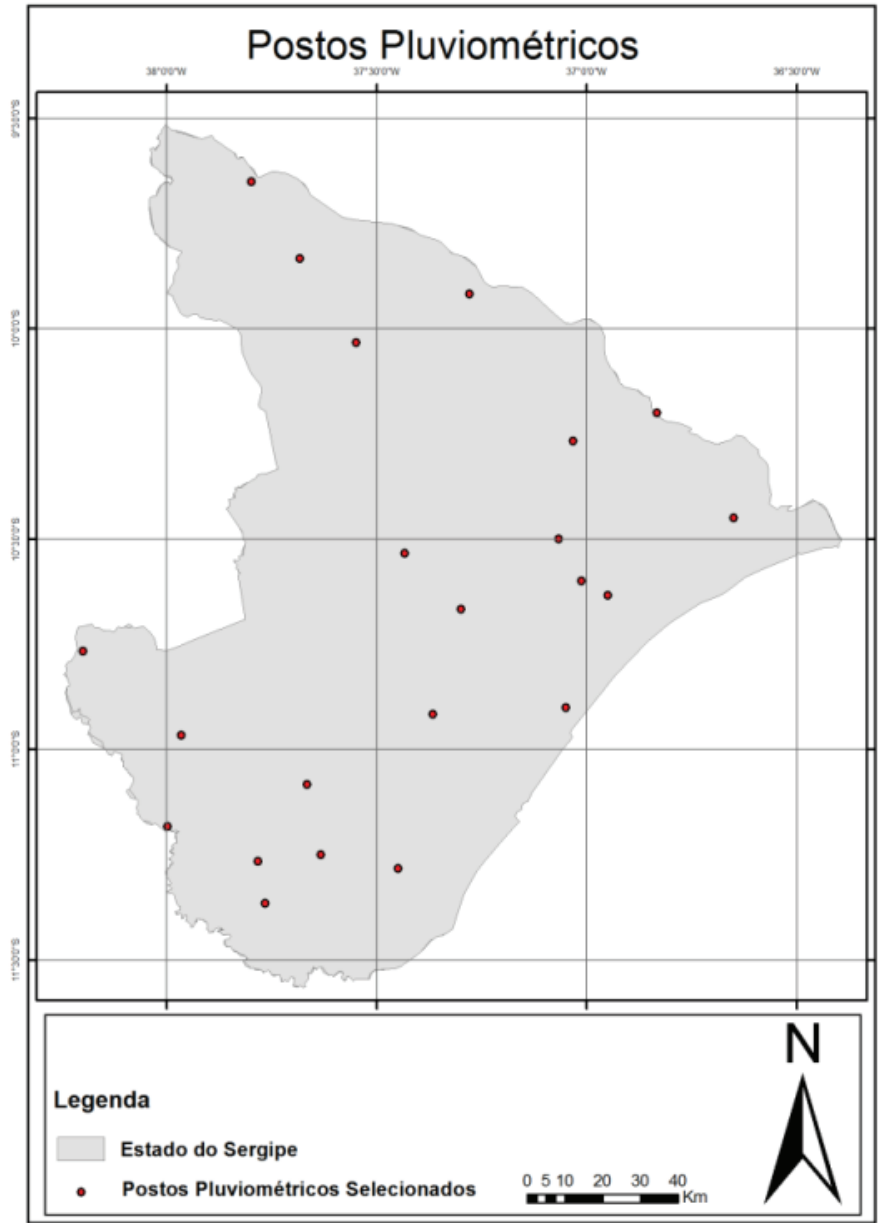

Fonte: Elaborado pelos autores a partir de dados da Sudene (1990). Dados tratados pelo DCA da UFCG. 
Os mensais de precipitação pluviométrica utilizados são os da série histórica da Superintendência do Desenvolvimento do Nordeste (Sudene, 1990) que tiveram suas médias mensais e anuais calculadas pelo Departamento de Ciências Atmosféricas (DCA) da Universidade Federal de Campina Grande, UFCG, disponibilizados na internet. A temperatura média foi estimada pelo mesmo DCA/UFCG e os dados também estão disponíveis na internet. Para a tabulação dos dados e a confecção dos gráficos, foi utilizado o Software Excel 2010, a partir destes, foram feitos os cálculos para chegar ao número de meses secos por ano, no Estado do Sergipe.

Para a elaboração dos climogramas e para o cálculo da quantidade de meses secos e a duração da estação chuvosa, assim como Nímer (1977), adotamos como critério o índice xerotérmico de Gaussen e Bagnouls (1953). Os autores consideram mês seco aquele cujo total das precipitações em milímetros é igual ou inferior ao dobro da temperatura média em Graus Celsius $(\mathrm{P} \leq 2 \mathrm{~T})$.

Com a obtenção e tabulação dos dados, foi elaborado um mapa temático da representação dos meses secos por ano no Estado. Para a confecção do referido mapa, foram usados os Softwares Arcgis10 e Corel DRAW GraphicsSuite X5.

A análise e a interpretação da importância do relevo, como elementos de explicação da distribuição dos climas no estado, foram feitas utilizando as bases cartográficas dos mapas de geologia e relevo disponíveis no Atlas digital da secretaria de estado do meio ambiente e dos recursos hídricos (Sergipe, 2011) com escala de 1:400.000; mapa geológico do estado produzido pelo CPRM (Santos et al., 2001), com escala 1:250.000, além da Folha Aracaju/Recife do Projeto Radambrasil (Nou; Bezerra; Dantas, 1983) que trata da geomorfologia e avaliação do relevo produzidas em 1983.

\section{Sistemas atmosféricos atuantes}

A Zona de Convergência Intertropical (ZCIT) é um dos principais sistemas responsáveis por precipitação pluviométrica nas baixas latitudes no território brasileiro:

Um conjunto de variáveis meteorológicas que atua sobre a faixa equatorial dos oceanos pode definir a ZCIT, a saber: a Zona de Convergência dos Alísios (ZCA), a região do cavado equatorial, as áreas de máxima Temperatura da Superfície do Mar (TSM) e de máxima 
convergência de massa, e a banda de máxima cobertura de nuvens convectivas. (Melo; Cavalcanti; Souza, 2009, p. 26)

A confluência dos alísios do Nordeste e do Sudeste e a convergência de massas em baixos níveis favorecem o transporte de umidade e o aumento da atividade convectiva, em especial sobre o NEB.

De acordo com Melo, Cavalcanti e Souza (2009), em relação ao Atlântico Equatorial, a ZCIT migra sazonalmente de sua posição mais ao norte, próximo aos $14^{\circ} \mathrm{N}$ (agosto-setembro), para a sua posição mais ao sul aproximadamente aos $2^{\circ} \mathrm{S}$ (março-abril). As autoras afirmam que "em anos chuvosos, a ZCIT pode atingir até $5^{\circ} \mathrm{S}$, perto da costa nordestina" (p. 25). Vale ressaltar que essas posições tratam do centro de atuação do sistema, em especial de sua banda principal, podendo ocorrer uma banda secundária (Figura 3) no Hemisfério Sul (HS), precipitações ocasionadas na margem desse sistema no Nordeste Setentrional são percebidas com

Figura 3: Imagem do satélite Goes-10 + Meteosat-9, ilustrando a ZCIT com uma banda principal e outra secundária em 29/4/2007, às 11:45 UTC.

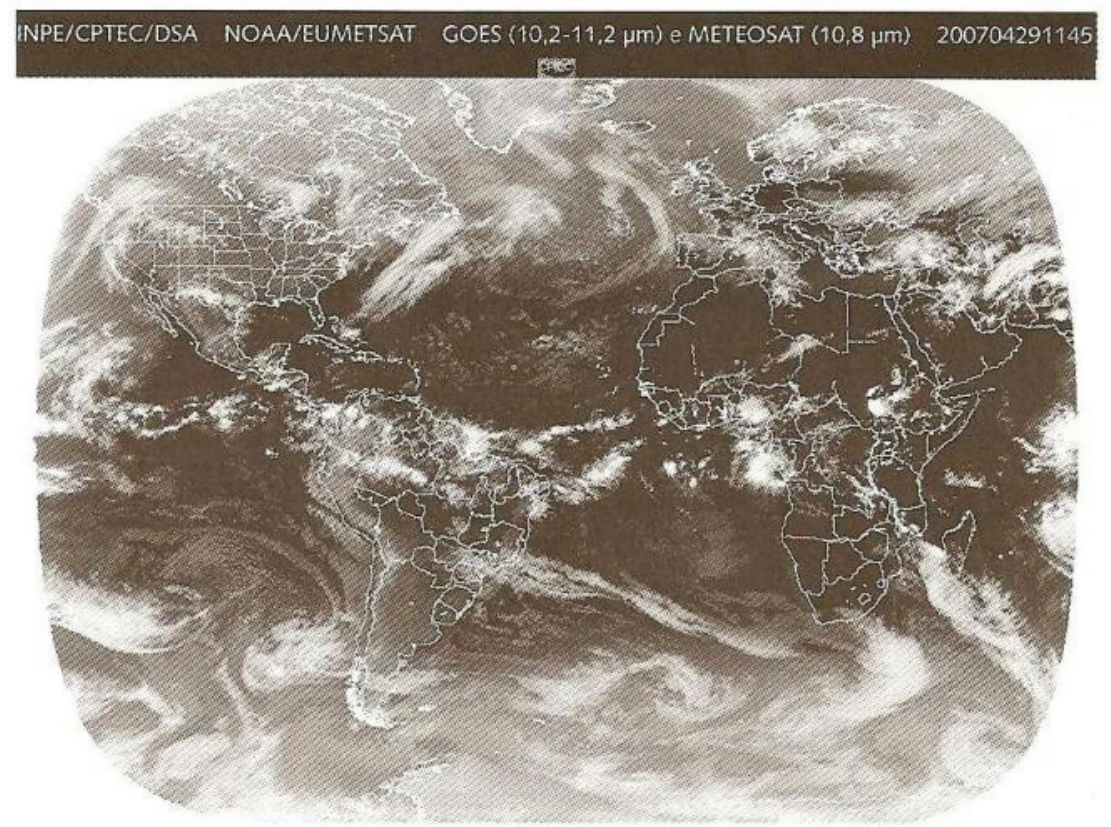

Fonte: Climanálise apud Melo; Cavalcanti; Souza, 2009. 
grande frequência no Sertão Pernambucano e a sul do Ceará, por exemplo; portanto, após os $8^{\circ} \mathrm{S}$ há áreas que recebem precipitação da citada banda secundária. Costa e Santos (2011) afirmam que precipitações associadas à ZCIT chegam a atingir o estado do Sergipe; na Figura 3, é possível perceber que a banda secundária chega a atingir o norte da Bahia.

A ZCIT tem, portanto, uma participação secundária nos totais de precipitação de Sergipe, dado que sua banda secundária não atua em todos os anos, apenas nos mais chuvosos; assim, há anos em que o sistema não chega a atingir o estado sergipano.

O outro mecanismo de grande escala que atua no NEB é o das frentes frias, entretanto, esse fenômeno está relacionado ao avanço da Massa Polar Atlântica (MPA) pela fachada litorânea do Brasil que será discutido no tópico subsequente.

Um fenômeno de mesoescala que tem grande influência sobre a área é o das Perturbações Ondulatórias no Campo dos Alísios (POA), que ocorrem graças à penetração profunda de sistemas frontais do HN em latitudes equatoriais. As POA se propagam para o oeste, cruzam o Equador, mas não se desenvolvem sobre o oceano, só se intensificam quando chegam à costa em virtude do aumento de convergência de umidade e ao contraste térmico continente-oceano (Molion e Bernardo, 2002). Se em fase com a brisa marítima chegam a penetrar $300 \mathrm{~km}$ para o interior do continente, se confluírem com a brisa terrestre podem provocar tempestades com precipitações superiores aos $50 \mathrm{~mm} /$ dia, o que ocorre, em geral, à noite.

Esses fenômenos ocorrem entre março e maio (originários da África) e entre junho e agosto (provenientes do Atlântico Sul). As POA são também chamadas de Distúrbios Ondulatórios de Leste (Machado et al., 2009) ou apenas Ondas de leste, e como estes nomes sugerem são provenientes do Leste, atingindo prioritariamente o litoral oriental do NEB, diminuindo sua atuação, à medida que ruma para o interior.

Brisas marinhas e terrestres têm sua influência restrita às áreas a menos de $150 \mathrm{~km}$ do Atlântico e promovem chuvas associadas a outro sistema, já as circulações orográficas, que se constituem em exemplos de mecanismos de microescala, não têm grande relevância em virtude da pequena expressão das formas de relevo do estado como será vista mais à frente. 


\section{Massas de ar atuantes no estado de Sergipe}

As principais massas de ar responsáveis por precipitações pluviométricas no Sergipe são a Massa Equatorial do Atlântico Sul (MEAS) que atua mais a noroeste do estado; a Massa Polar Atlântica (MPA) e a Massa Tropical Atlântica (MTA) que atuam prioritariamente no restante do estado e são bastante influenciadas pela continentalidade.

A MPA se origina nas altas polares e é atraída pelas baixas equatoriais, rumo ao Equador pela faixa leste do Brasil. Apesar de originariamente essa massa ser fria e seca, ganha umidade e perde temperatura em seu trajeto às menores latitudes, ela produz chuvas no litoral brasileiro entre finais de verão e inverno e sua atuação diminui bastante à medida que se afasta da costa (Mendonça; Danni-Oliveira, 2007).

Além disso, a MTA é uma das principais massas de ar, fato que auxilia na compreensão da dinâmica atmosférica do Brasil, onde há considerável influência na definição dos tipos climáticos; origina-se no centro de altas pressões subtropicais de altas pressões do Atlântico e apresenta, portanto, características de temperatura e umidade elevadas. Também é atraída por baixas pressões continentais, abastecendo o continente com umidade e calor; atua durante o ano inteiro sobre o Brasil, especialmente no verão e nas faixas litorâneas, à medida que ruma para o interior perde muito de sua umidade (Mendonça; Danni-Oliveira, 2007).

\section{A participação do relevo na distribuição da pluviosidade}

Compreender como é a distribuição e a morfologia do relevo pela superfície terrestre é importante para justificar a diferenciação climática em várias regiões do planeta, contribuindo para maiores níveis de pluviosidade a barlavento e menor pluviosidade a sotavento.

Nesse sentido, a continentalidade e a maritimidade são os principais fatores geográficos do clima no estado do Sergipe, já que o relevo não tem grande importância nos totais de precipitação pluviométrica.

O relevo de Sergipe é pouco movimentado, constituído por um modelado suave com áreas planas e altitudes modestas que, de modo geral, vão aumentando em direção ao interior, interrompido localmente por elevações de serras residuais que constituem os pontos mais eleva- 
dos do estado. No estado de Sergipe, a influência do relevo é modesta, restringindo-se a situações pontuais sem expressar magnitude suficiente para determinar tipos climáticos específicos. As baixas altitudes predominantes no estado são representadas por relevos dissecados em colinas, interflúvios tabulares e superfícies pediplanadas (Nou; Bezerra; Dantas, 1983).

A partir da análise da distribuição e das formas de relevo de Sergipe, observa-se o predomínio de unidades de baixa altitude; existem formas entre 400 e 659 metros de altitude no centro do estado, constituídas por rochas que datam do mesoproterozoico, neoproterozoico e paleoproterozoico, representadas pelo Grupo Miaba (Formação Jacoca, Ribeirópolis e Itabaiana), sendo a Serra de Itabaiana a de maior elevação no estado, com 659 m de altitude. Ainda segundo Nou, Bezerra e Dantas (1983), já no noroeste e sudoeste ocorrem, respectivamente, as unidades de Planaltos de Serra Negra e de Sudoeste constituindo-se em maciços residuais de topo aplainado com seus rebordos apresentando inúmeras elevações em torno de 500 metros.

A pequena participação do relevo no clima de Sergipe se dá para aumentar os totais pluviométricos a barlavento dos planaltos e serras, especialmente nas vertentes mais a sudeste. Esse fato justifica a maior precipitação pluviométrica para os municípios a barlavento da Serra de Itabaiana em relação ao município de Itabaiana que se encontra a sotavento. Uma vez que os ventos predominantes são os persistentes alísios de sudeste (Figura 4), o padrão geral do clima do estado é o de aumentar os totais pluviométricos, bem como a quantidade de meses chuvosos nas porções mais a sudeste, ocorrendo o inverso a noroeste do estado, o que atesta a enorme importância da continentalidade na elaboração dos tipos climáticos do estado.

Quanto às temperaturas médias, em geral, as modestas elevações não causam grandes amplitudes no estado. 
Figura 4: Mapa do relevo de Sergipe com destaque para a direção predominante dos ventos e alguns postos pluviométricos selecionados para exemplificar os tipos climáticos.

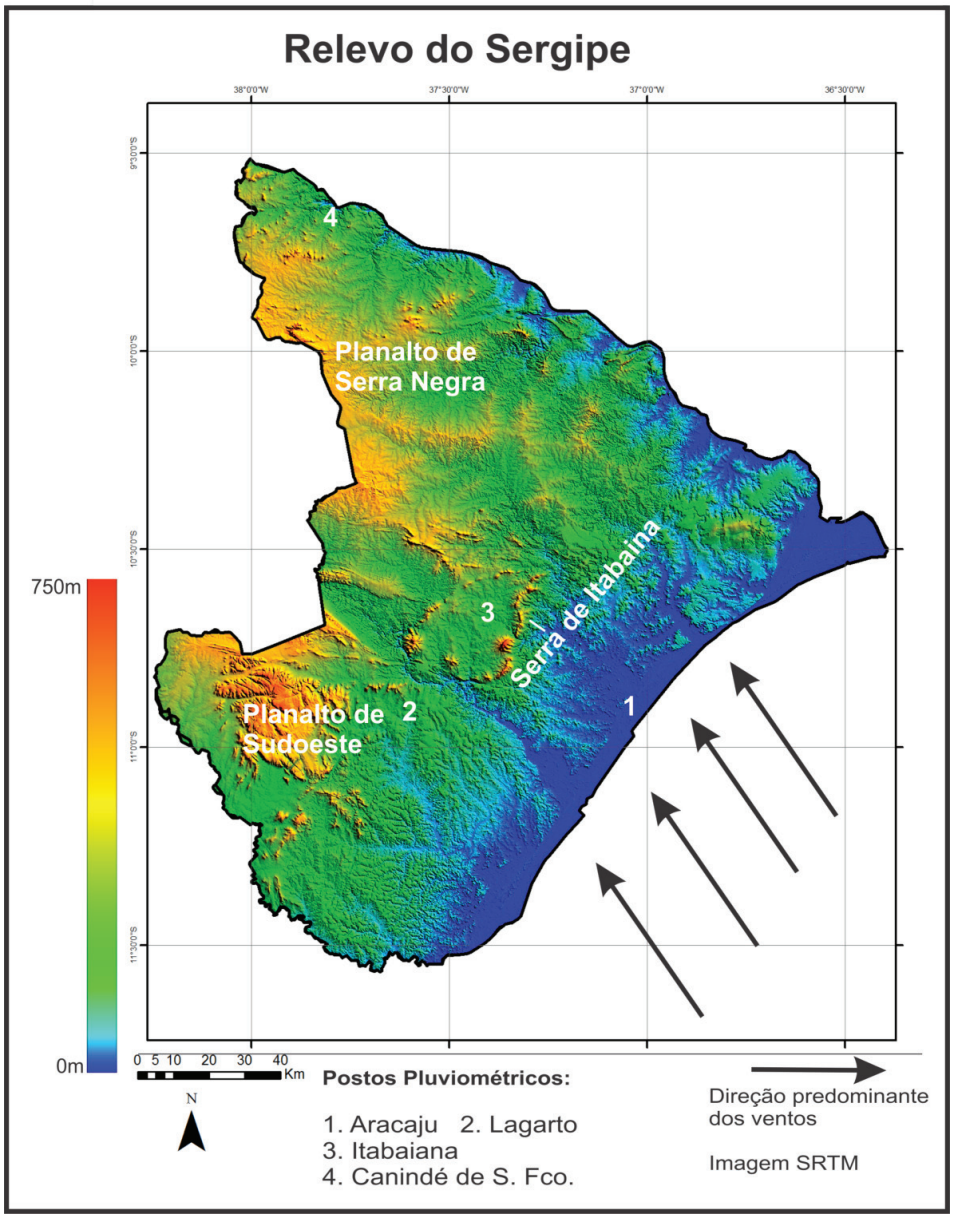

Fonte: elaborado pelos autores a partir de imagem SRTM.

Análise dos dados termopluviométricos e discussão

O regime pluviométrico e o número de meses secos no estado de Sergipe variam de acordo com a época do ano e a localização geográfica. O índice de precipitação se distribui de forma decrescente do litoral para o interior do estado. O litoral mais a sudeste apresenta apenas de 0 a 2 me- 
ses secos, enquanto o noroeste do estado apresenta de 7 a 8 meses secos, como mostra a Figura 5.

Figura 5: Massas de ar atuantes e tipos climáticos no estado de Sergipe.

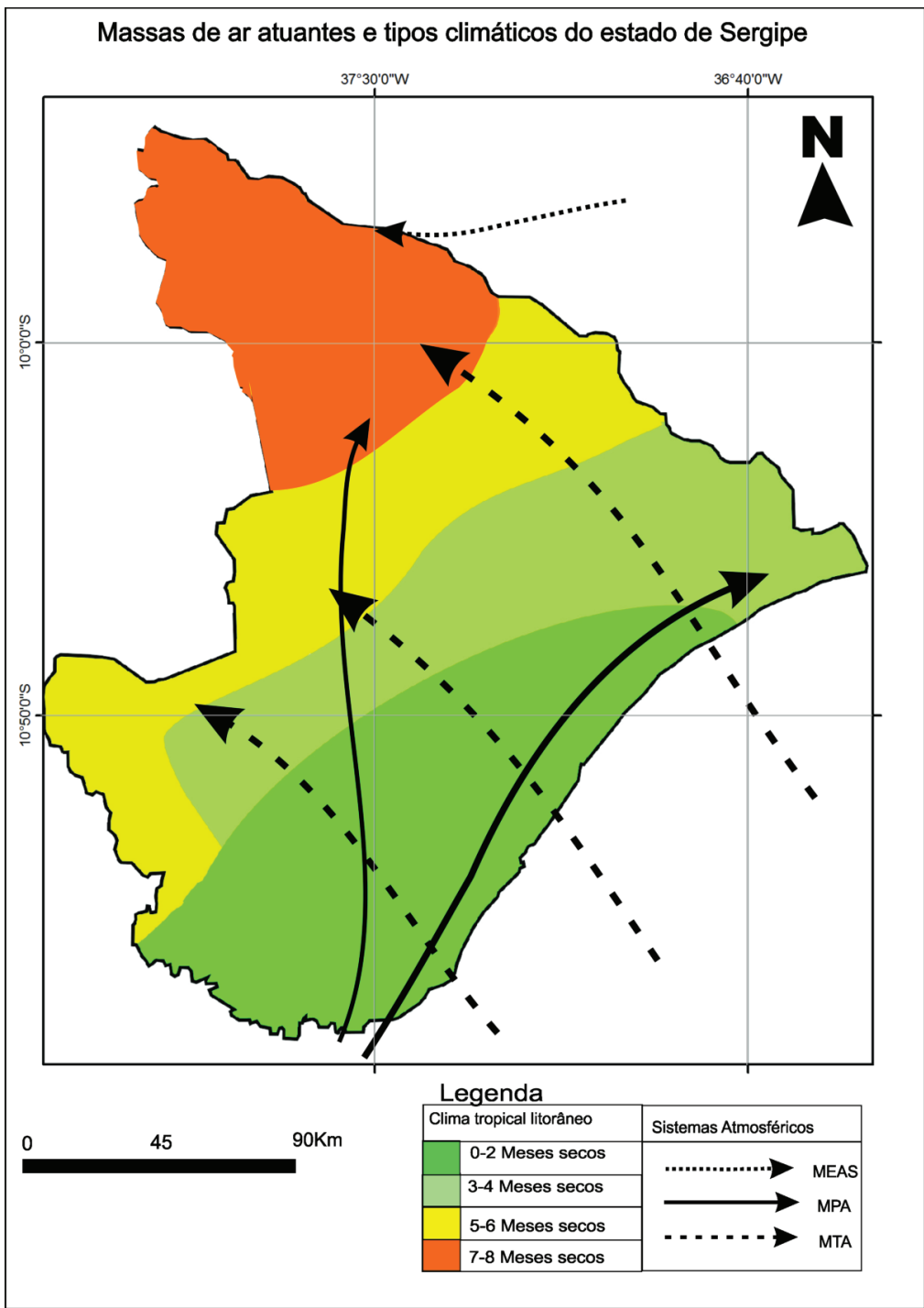

Fonte: Elaborado pelos autores a partir de dados da Sudene (1990). 
No litoral sergipano, praticamente não há meses secos (à exceção do trecho mais a nordeste), a atuação da MTA empurrada para o continente durante o ano inteiro pelos persistentes ventos alísios de sudeste (Figura 4) são os principais responsáveis por essa situação de boa distribuição das chuvas durante o ano inteiro com total anual de $1579 \mathrm{~mm}$ em média.

O Gráfico 1 mostra a distribuição da precipitação da cidade de Aracaju/SE, os dados representam bem o clima tropical litorâneo sem seca, entretanto é possível perceber que em fins de primavera a taxa pluviométrica tende a crescer com máxima de outono-inverno, o que Nímer (1977) denomina regime de chuvas mediterrâneo.

Gráfico 1: Climograma com temperatura e precipitação (médias mensais) em Aracaju/SE.

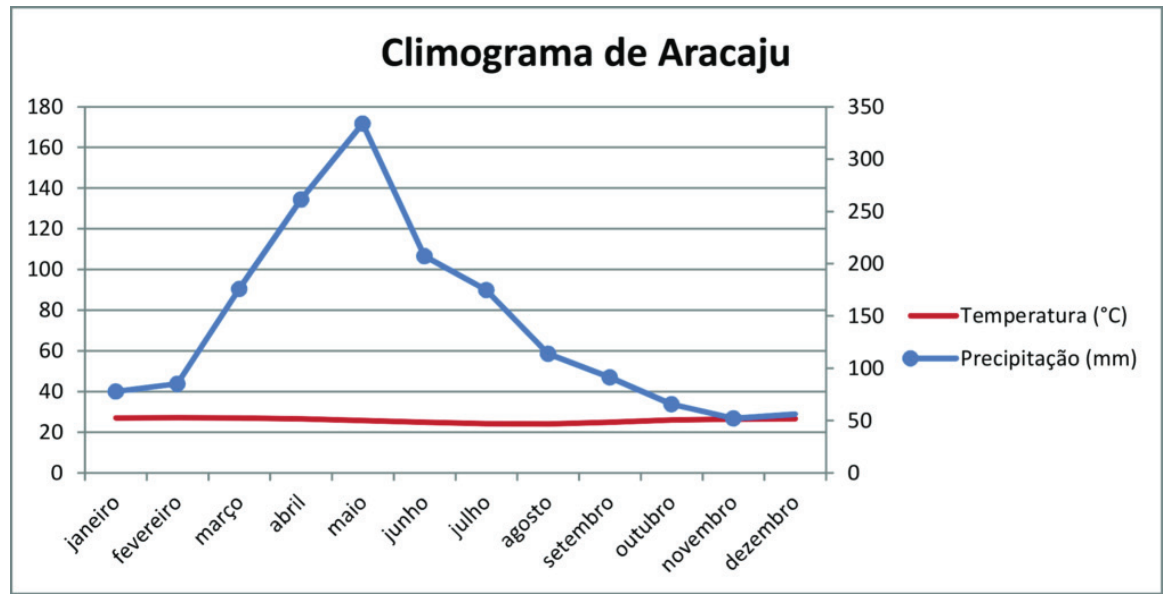

Fonte: Elaborado pelos autores a partir de dados da Sudene (1990) e DCA/UFCG.

As cidades próximas do litoral sergipano têm no máximo dois meses secos (exceto o trecho mais a nordeste) graças à atuação das principais massas de ar (MTA e MPA) que se concentram especialmente no litoral. A frente decorrente da atuação dessas massas de ar promove queda na temperatura e chuvas frontais mais intensas de outono/inverno, ou seja, entre os meses de abril e agosto.

O mês de maio é o mais chuvoso. Neste mês tem-se por vezes a atuação da MEAS associada à MTA e é, sobretudo, o período de início mais forte das chuvas associadas à MPA; as frentes frias têm suas principais 
incursões feitas no inverno, o que tende a baixar um pouco a temperatura e elevar a taxa média de precipitação do litoral, já que ela chega a Sergipe carregada de umidade adquirida em sua marcha sobre o Atlântico. Outro fator que contribui para uma maior precipitação em maio é o fato de que as POA tendem a atuar com maior força no litoral sergipano a partir desse mês.

Deslocando-se em direção ao interior do estado, observa-se que a duração da estação seca começa a aumentar numa transição para a semiaridez do sertão. Existem duas faixas subúmidas, uma mais próxima ao litoral com 3 a 4 meses secos como em Lagarto (Gráfico 2).

Gráfico 2: Climograma com temperatura e precipitação (médias mensais) em Lagarto/SE.

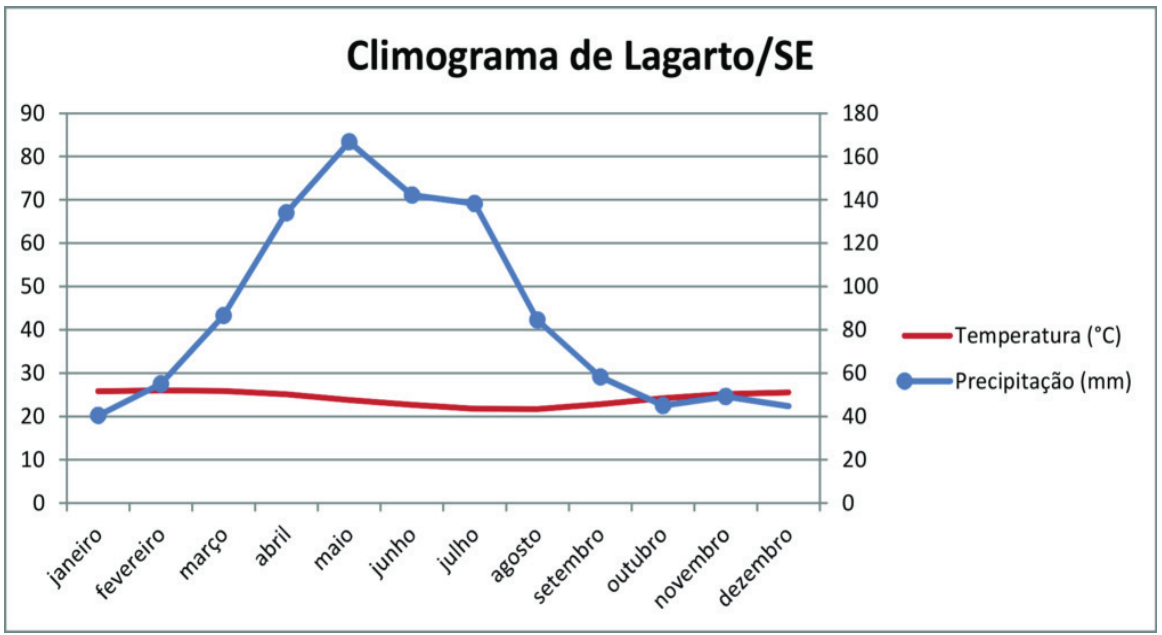

Fonte: Elaborado pelos autores a partir de dados da Sudene (1990) e DCA/UFCG.

O município de Lagarto tem cerca de 4 meses secos, mas apresenta o mesmo regime de chuvas de Aracaju, com máximas de outono/inverno, sendo o mês de maio o mais chuvoso; isso acontece pelo fato de essas cidades estarem submetidas aos mesmos sistemas promotores de chuvas, visto que a diferença na duração da estação seca e nos totais pluviométricos médios anuais é explicada pela continentalidade. Lagarto se encontra a leste do Planalto de Sudoeste (Figura 4) e não tem nenhuma barreira orográfica a sudeste, o que anula a importância do relevo no regime precipitação. 
A outra faixa de transição é a de 5 a 6 meses secos. Assim como Lagarto, a cidade de Itabaiana também tem o clima subúmido do agreste sergipano; entretanto, nesta cidade, o efeito orográfico é percebido por estar localizada a sotavento da serra homônima (Figura 4). A estação seca é um pouco mais duradoura que em Lagarto, com 5 meses secos (Gráfico 3), assim como o total de precipitação pluviométrica média anual é inferior pelo mesmo motivo, sendo de 896,5 mm em Itabaiana contra 1031,8 mm em Lagarto, essas taxas médias são consideravelmente inferiores às de Aracaju, o que atesta a relevância da continentalidade/maritimidade sobre os dados pluviométricos para o estado.

Gráfico 3: Climograma com temperatura e precipitação (médias mensais) em Itabaiana/SE.

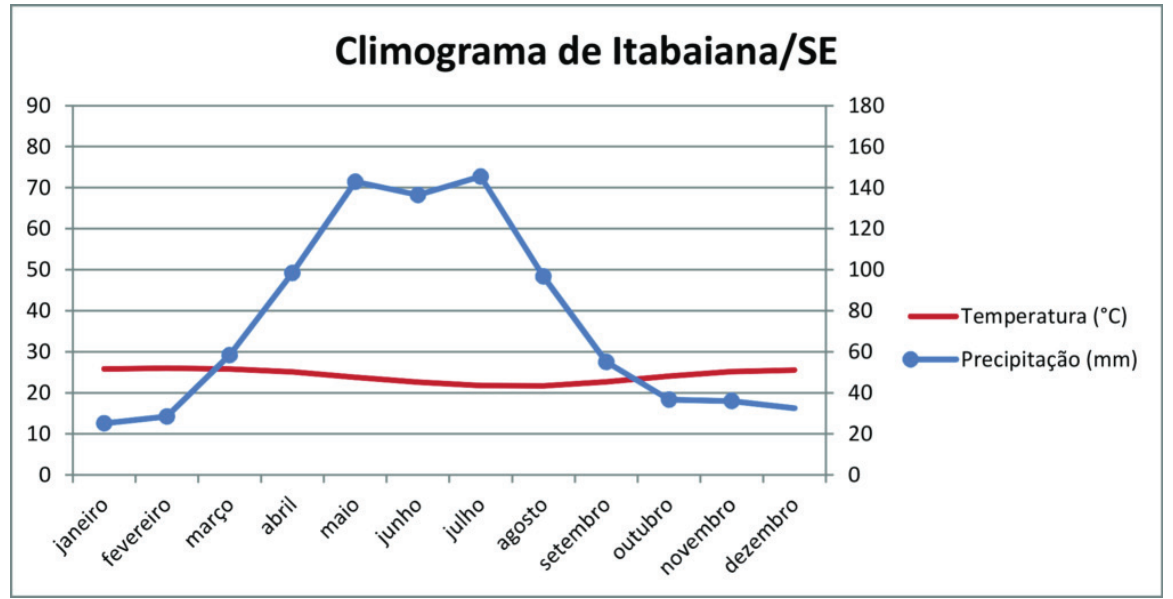

Fonte: Elaborado pelos autores a partir de dados da Sudene (1990) e DCA/UFCG.

Em Itabaiana, os meses mais chuvosos ocorrem entre maio e julho e a estação seca tem início no fim do inverno quando deixam de ocorrer as incursões da MPA. O ritmo e a distribuição da pluviosidade no município de Itabaiana não diferem de outros municípios do Agreste, como é o caso do município de Lagarto, pois eles se estendem numa mesma faixa longitudinal, inclusive com distanciamento aproximado em relação ao litoral, comprovando a importância da continentalidade na compreensão da dinâmica climática do estado.

Já no extremo noroeste do Sergipe, a precipitação torna-se bem mais escassa, com o aumento da estação seca para o nível de 7 a 8 meses secos. 
O Gráfico 4 mostra o regime de precipitação na cidade de Canindé de São Francisco, localizada no extremo noroeste do Sertão Sergipano (Figura 4). Apesar de manter o mesmo regime com máximo índice pluviométrico no mês de maio e sendo influenciado pelas mesmas massas de ar do litoral, a continentalidade se apresenta como fator limitante para a atuação da MTA e, em especial, da MPA que não avançam muito para longe do litoral. Vale ressaltar que, quando ocorre esse fato, o tempo de atuação dessas massas é bem menor, diminuindo o número de meses úmidos.

O posto pluviométrico de Canindé de São Francisco apresenta 7 meses secos, sua estação chuvosa acontece entre os meses de março e julho, com máximo de cerca de $62 \mathrm{~mm}$ em maio e mínimo de cerca de 13 $\mathrm{mm}$ em outubro. Os cerca de $60 \mathrm{~mm}$ de precipitação em março atestam a participação da ZCIT (através da MEAS) nas chuvas no extremo noroeste do estado. Entretanto, o regime de chuvas pode ser também considerado mediterrâneo como no restante do estado, posto que a maior parte da precipitação se dá no outono/inverno.

Gráfico 4: Climograma com temperatura e precipitação (médias mensais) em Canindé de São Francisco/SE.

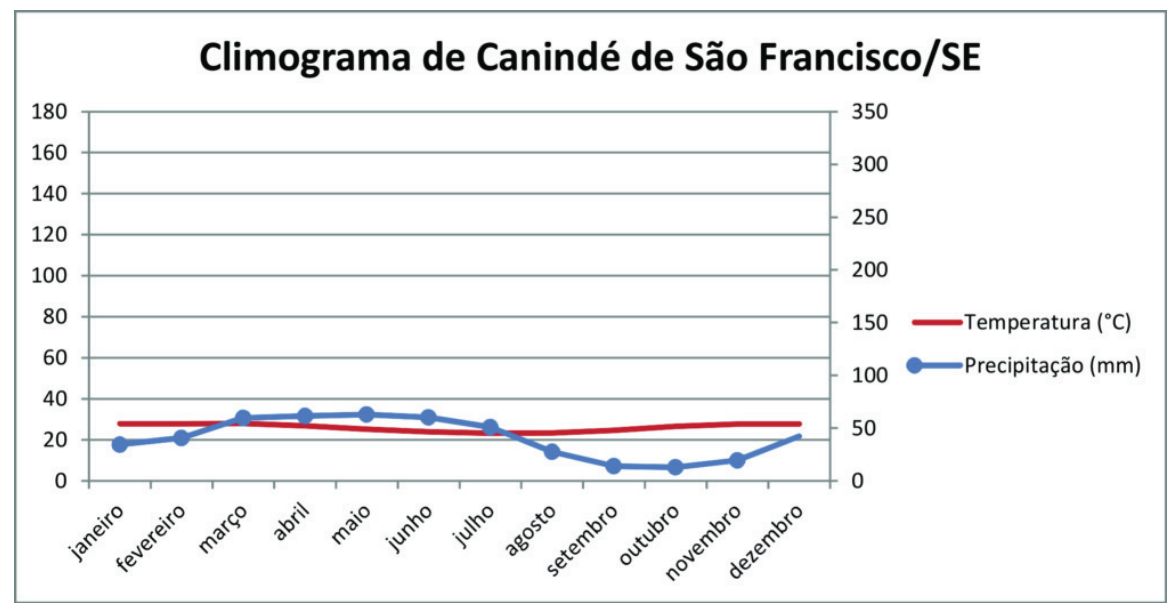

Fonte: Elaborado pelos autores a partir de dados da Sudene (1990) e DCA/UFCG.

Em Canindé de São Francisco, sentem-se as incursões da MPA muito mais em relação à temperatura média, que decresce razoavelmente no inverno, do que em relação à precipitação, já que grande parte da umi- 
dade que esta massa carrega para o continente precipita ainda na faixa litorânea, mais a sudeste do estado.

Dadas as massas de ar atuantes, o estado inteiro do Sergipe pode ter seu clima classificado como tropical litorâneo de regime mediterrâneo, com máximas de outono/inverno. Contudo, apesar de razoavelmente bem distribuídos, os 488,1 mm/ano em média, em Canindé de São Francisco, atestam o padrão de semiaridez que este tipo climático alcança no sertão sergipano (a noroeste do estado); nessa parte do estado, há mesmo uma transição para o clima tropical equatorial que apresenta máximas de verão/outono predominantes no sertão nordestino, excluindo-se o sertão baiano e o sergipano.

\section{Considerações finais}

O estado de Sergipe apresenta um volume e uma distribuição da precipitação pluviométrica associados à interferência da Zona de Convergência Intertropical (ZCIT) que atua mais a noroeste do estado; a Massa Polar Atlântica (MPA) e a Massa Tropical Atlântica (MTA) atuam prioritariamente no restante do estado.

A continentalidade e a maritimidade exercem grande influência na distribuição pluviométrica e definem os principais tipos climáticos do estado que ocorrem respectivamente do litoral mais a sudeste para o interior mais a noroeste; os padrões de clima úmido (de 0 a 2 meses secos) atuam especialmente na zona da mata sergipana, na faixa dos tabuleiros; o clima subúmido de transição para o semiárido (de 3 a 4; e de 5 a 6 meses secos) no Agreste; e o semiárido (de 7 a 8 meses secos) na porção interiorana onde ocorrem áreas de pediplano sertanejo e serras residuais.

O relevo sergipano, predominantemente de baixas altitudes, não se caracteriza como fator de destaque na definição dos climas e da distribuição da pluviosidade, exceto em áreas pontuais e de pequena amplitude representada pelas vertentes de barlavento de algumas serras residuais, especialmente na região central onde ocorre o Domo de Itabaiana e nos planaltos do Sudoeste e de Serra Negra.

\section{Agradecimentos}

Os autores agradecem ao colega Prof. MSc. Gisonaldo Arcanjo de Sousa pela revisão ortográfica feita neste artigo. 


\section{Referências}

COSTA, O. A.; SANTOS, D. N. dos. Influência da ZCAS e ZCIT e seus efeitos de inundações nas bacias hidrográficas no estado de Sergipe, abril de 2010. In: ENCONTRO DE RECURSOS HÍDRICOS EM SERGIPE, 4, Aracaju. Anais eletrônicos... Aracaju: Embrapa, CPTAC, 2011. 23 a 25 de março de 2011, Aracaju/SE. Disponível em: <http://www.cpatc.embrapa.br/publicacoes_2011/anais_4enrehse/Resumos_expandidos/INFLU\%C3\%8ANCIA\%20DA\%20Z̄CAS\%20E $\% 20 Z C I T \% 20$ E\%20SEUS\%20EFEITOS\%20DE\%20INUNDA\%C3\%87\%C3\%95ES\%20NAS\%20 BACIAS\%20HIDROGR\%C3\%81FICAS\%20NO\%20ESTADO\%20DE\%20SERG_0. pdf $>$. Acesso em: 8 maio 2012.

DEPARTAMENTO DE CIÊNCIAS ATMOSFÉRICAS (DCA). Universidade Federal de Campina Grande (UFCG). Clima. Campina Grande. Disponível em: <http:// www.dca.ufcg.edu.br/clima/>. Acesso em: 10 ago. 2012.

GAUSSEN, H.; BAGNOULS, F. Saison sèche et índice xérothermique. Université de Toubouse, Faculté des Sciences, 1953.

MACHADO, L. A. T.; FERREIRA, N.; LAURENT, H.; DIEDHIOU, A. Distúrbios ondulatórios de leste. In: CAVALCANTI, I. F. A.; FERREIRA, N. J.; SILVA, M. G. A. J.; DIAS, M. A. F. S. (Orgs.). Tempo e clima no Brasil. São Paulo: Oficina de Textos, 2009. p. 61-74.

MELO, A. B. C.; CAVAlCANTI, I. F de A.; SOUZA, P. P. Zona de Convergência Intertropical do Atlântico. In: CAVALCANTI, I. F. A.; FERREIRA, N. J.; SILVA, M. G. A. J.; DIAS, M. A. F. S. (Orgs.). Tempo e clima no Brasil. São Paulo: Oficina de Textos, 2009. p. 26-42.

MENDONÇA, F.; DANNI-OLIVEIRA, I. M. Climatologia: noções básicas e climas do Brasil. São Paulo: Oficina de Textos, 2007.

MOLION, L. C. B.; BERNARDO, S. O. Uma revisão da dinâmica das chuvas no nordeste brasileiro. Revista Brasileira de Meteorologia, Rio de Janeiro, v. 17, n. 1, p. 1-10, 2002.

NÍMER, E. Clima. In: BRASIL. Instituto Brasileiro de Geografia e Estatística (IBGE). Geografia do Brasil: Região Nordeste. Rio de Janeiro: IBGE, 1977.

NOU, E. A. V.; BEZERRA, L. M. M.; DANTAS, M. Geomorfologia. In: BRASIL. Ministério das Minas e Energia. Secretaria Geral. Projeto Radambrasil, Folhas SC.24/25 Aracaju/Recife; geologia, geomorfologia, pedologia, vegetação e uso potencial da terra. Rio de Janeiro, 1983. p. 377-444.

SANTOS, R. A.; MARTINS, A. A. M.; NEVES, J. P. da N.; LEAL, R. A. (Orgs.). Programa Levantamentos Geológicos Básicos do Brasil (PLGB). Geologia e recursos minerais do Estado de Sergipe. Escala 1:250.000. Texto explicativo do Mapa geológico do Estado de Sergipe. Brasília: CPRM/DIEDIG/DEPAT; CODISE, 2001.

SERGIPE (Estado). Secretaria de Estado do Meio Ambiente e dos Recursos Hídricos (SEMARH). Superintendência de Recursos Hídricos do Estado de Sergipe. Atlas digital sobre os recursos hídricos de Sergipe. Aracaju, 2011.

SUDENE. Superintendência do Desenvolvimento do Nordeste. Dados pluviométricos mensais do Nordeste. Recife, 1990. (Série Pluviometria 1 a 10). 
Marco Túlio Mendonça Diniz - Possui Graduação em Geografia pela Universidade Estadual do Ceará, Mestrado e Doutorado em Geografia pela mesma universidade. Atualmente é professor da Universidade Federal do Rio Grande do Norte.

Sebastião Carlos de Medeiros - Possui Graduação em Geografia pela Universidade Federal do Rio Grande do Norte. Atualmente faz Especialização em Educação Ambiental e Geografia do Semiárido pelo Instituto Federal de Educação, Ciência e Tecnologia do Rio Grande do Norte.

Cleidinilson de Jesus Cunha - Possui Graduação em Geografia pela Universidade Federal de Sergipe e Mestrado em Agroecossistemas pela mesma universidade. Atualmente é Doutorando em Geografia pela Universidade Estadual do Ceará e professor do Instituto Federal da Bahia.

Recebido para publicação em 28 de novembro de 2013 Aceito para publicação em 7 de fevereiro de 2014 